\title{
Elastic properties of snow-ice formations in their whole density range
}

\author{
Anatoly D. Frolov, Igor V. Fedyukin \\ United Scientific Council on Earth Cryology of the Russian Academy of Sciences, Fersman Street 11, Moscow 117312, Russia
}

\begin{abstract}
The available experimental data on acoustic parameters and dynamic elastic moduli of dry coherent snow-ice formations in their whole density range are analysed and generalized in this paper. A set of critical densities at which there are sufficiently sharp changes in the laws of these property variations have been discovered and are discussed. The empirical equations describing the elastic-wave propagation velocities $\left(V_{\mathrm{p}}\right.$ and $V_{\mathrm{s}}$ ), acoustic resistivities and elastic moduli as functions of the porosity factor of the medium are obtained for five sub-ranges in the density range from light snow to massive ice.
\end{abstract}

\section{INTRODUCTION}

The structure-texture transformations which occur during dry-snow densification and diagenesis cause changes in its acoustic, elastic, strength and other properties. The direct experimental study of these transformations is difficult because data accumulation occurs rather slowly. However, up to the present time, considerable experimental data have been obtained and some theoretical concepts about the character of the snow-structure re-organization have been developed thanks to the work of many scientists. For example, it has been known for some time that there are two critical densities: 550 and $820 \mathrm{~kg} \mathrm{~m}^{-3}$ (Anderson and Benson, 1963). The first one characterizes the state of dry dense snow with completely proximate grains, i.e. some limit of the medium random densification and secondly the transition to ice with closed pores. It is also known that fresh light snow is characterized by a very friable chained structure with a coordination number varying from 2 to 3 . However, how the structural changes occur during a medium densification from a light to a dense state and at what density the new dominant space order arises remains unclear.

Are snow-property changes monotonous during densification? Known critical densities (mentioned above) testify to none of these monotonous processes. It is hardly possible to imagine an identical and continuous mechanism of snow densification from a light $\left(\rho \sim 30-50 \mathrm{~kg} \mathrm{~m}^{-3}\right)$ to a dense $\left(\rho \sim 550 \mathrm{~kg} \mathrm{~m}^{-3}\right)$ one. However, until recently, there were practically no data about critical densities in these snow states. Only in a few papers (for instance, Samoylyuk, 1992; Voronkov and Frolov, 1992) were there indications of an opportunity for critical densities below $550 \mathrm{~kg} \mathrm{~m}^{-3}$. It is obvious that the problems of critical densities are important for the development of the concept of snow mechanical property-formation processes and laws for its changes. They are closely related to the snow-structure transformation regularities of importance in snow-cover strength and estimates of bearing ability, achievements of explosions in snow, registration of acoustic signals from various moving and immobile sources of elastic oscillations, etc. Moreover, the acoustic and elastic parameters of porous media are very sensitive to their structural organizations. This refers to the elastic waves which propagate in the skeleton of the porous media (the waves of first arrival), with velocities determined by the compressibility of both the ice grains and the pores (Bourbie and others, 1986). The waves of the second kind (air waves) have not been considered.

Therefore, we have undertaken the present investigation to analyse in detail the available seismo-acoustic data in order to reveal the main regularities of the transformation features of the mechanical properties in the whole density range of snow-ice formations.

\section{BACKGROUND}

The experimental study of inter-relations between acoustic properties, elastic moduli of snow-ice formations and their densities have been the objective of many researchers (Bentley, Brockamp, Chernigov, Durynin, Kohnen, Maeno, Pounder, Robin, Smith, Yamada and others). Reviews of the results obtained by these authors, given by Macheret (1977), Mellor (1977), Voitkovskiy (1977), Bogorodskiy and Gavrilo (1980) and Paterson (1994), contain the experimental data and empirical formulae, which have been proposed to describe the changes in the acoustic parameters within some density intervals. However, authors have usually aimed to present laws in a form of continuous (linear or non-linear) functions and spread them over a wide density range. It is unlikely that by using this expedient general regularities of acoustic- and elastic-property changes can be found. In addition, most of studies have been conducted using snow of densities of $350-400 \mathrm{~kg} \mathrm{~m}^{-3}$ and higher.

The properties of friable snow have been poorly investigated. This is due to the difficulties of their study by ultrasonic methods, because it is necessary to remove the sensor's dimensions and to create a perfect contact between the sensors and the snow. In our experiments, in order to ensure perfect contact we used both special synthetic oils and ice bridges.

The main difficulty in generalizing from the different data is the difference between experimental procedures and that none of the snow-ice media studied are identical or even at the same or similar densities and temperatures. For example, in Mellor's review, the experimental data of 


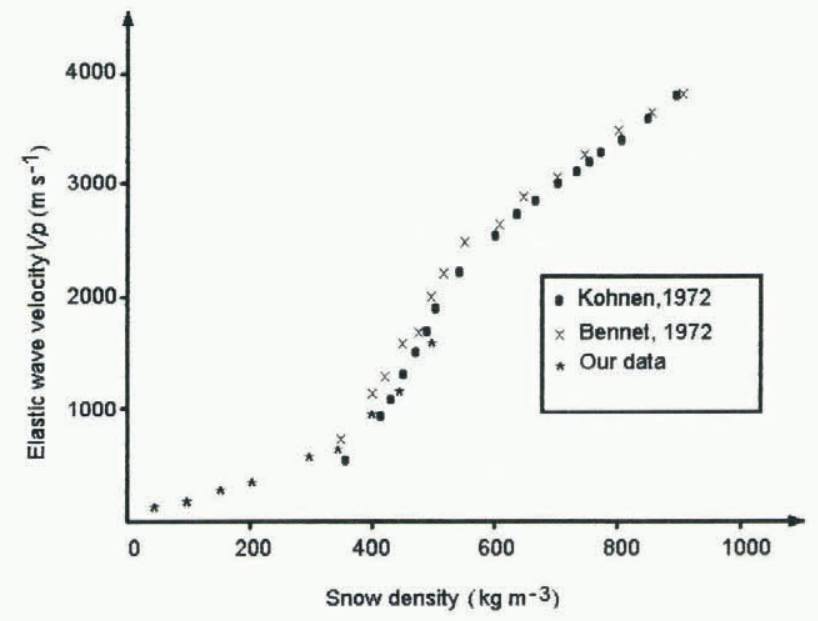

Fig. 1. Longitudinal wave velocity $V_{\mathrm{p}}$ vs snow density from different authors.

many authors have been presented in the form of intervals (bands) of values, the width and representativeness of which are difficult to estimate.

Therefore, we have selected as the basis for analysis the seismic field data for the elastic-wave velocities of Bennet (1972), Kohnen (1977) and Kohnen and Bentley (1973) for Antarctica and Greenland (snow density $350 \mathrm{~kg} \mathrm{~m}^{-3}$ and higher) and our partly published (Savel'yev and others, 1967; Frolov, 1976) data obtained in the Kolskiy Peninsula (snow density from $30-50$ to $500 \mathrm{~kg} \mathrm{~m}^{-3}$ ).

Our data for light snow were obtained by an ultrasonic pulsing method (with the P-and S-wave sensors of a dominant frequency of $50-100 \mathrm{kHz}$ ) in special pits dug in the snow cover. The measurements were achieved by profiling (with a special sensor-assembly plan) and transmitting technology. The necessary acoustic contact between the sensors and the grains of snow were ensured by using silicon oil, glycerine or by freezing. The measurements were repeated 30-50 times for those layers with a close density, age and structure, and for each such series the mean (the most probable) values of elastic-wave velocities were determined. We did not take into account the dependency of the acoustic parameters on the temperature and humidity of the snow. All the data presented below correspond to dry coherent snow at temperatures near $-10^{\circ}$ to $-15^{\circ} \mathrm{C}$.

The first comparison of these data has shown a very good convergence of the elastic-wave velocity values obtained in the overlapping interval of snow density (Fig. 1) and has revealed a new critical density $\rho \sim 330 \mathrm{~kg} \mathrm{~m}^{-3}$ (Voronkov and Frolov, 1992). The dependency of the velocities $V_{\mathrm{p}}$ and $V_{\mathrm{s}}$ on density appeared to be linear with a different slope in the various intervals between the critical densities. Comparison with other published data (Macheret, 1977; Mellor, 1977; Voitkovskiy, 1977; and others) has not revealed any important contradictions.

On the basis of the above-mentioned experimental data on elastic velocities and densities, we have calculated (using as a first approximation the known formulae from the theory of elasticity of continuous media) the values of the acoustic resistivities $Z_{\mathrm{p}}$ and $Z_{\mathrm{s}}$ and Young's elastic modulus $E$, shear modulus $G$, bulk modulus $K$, Poisson's ratio $\nu$ and Lamé's constant $\lambda$ as parameters for snow-ice formation.

Statistical analysis of these data led us to conclude that snow-ice formation acoustic- and elastic-parameter changes in the whole density range cannot be described satisfactorily by a specific smooth function for density (or porosity), including a polynome of a reasonable degree, up to one-fifth.

The availability of sufficiently sharp changes in the density dependencies of acoustic parameters reflects the fact that during snow densification and metamorphism the structuretexture re-organization has different prevailing mechanisms of transformation in the various density intervals. The transitions of a medium from one state to another (which can be considered as analogues of structural-phase transitions of the second type) should take place near some critical values (narrow intervals) of density. At these densities, the degree of structure-space order (structural entropy) and rigidity appear to reach some boundary values, which lead to replacement of the dominant mechanisms and regularity of mechanical-property changes. However, representation of experimental data as a function of snow density $\rho$ or porosity $P$ allows one to reveal the boundary states of structural transformations only to a rough approximation. Therefore, we have undertaken a search for a new parameter of comparison which is more sensitive to snow-medium structural changes.

\section{RESULTS AND DISCUSSION}

We have established that the best parameter of comparison, which enables the revelation of the boundary states of snowstructural transformations more precisely and approximates the laws of acoustic- and elastic-property changes, is the porosity factor $K_{\mathrm{p}}$ of a medium:

$$
K_{\mathrm{p}}=V_{\text {por }} / V_{\text {sol }}=P /(1-P)=\left(\rho_{\mathrm{i}}-\rho\right) / \rho
$$

where $\rho_{\mathrm{i}}=917 \mathrm{~kg} \mathrm{~m}^{-3}$ is the density of massive ice, $V_{\text {por }}$ and $V_{\text {sol }}$ are the volume of pores and the solid part of a medium, respectively. For snow-ice formations, the value of $K_{\mathrm{p}}$ lies within the limits of 0 to 30 . According to the theory of granular media, the porosity factor $K_{\mathrm{p}}$ correlates with the grainsize and the corresponding pore volume. So, this parameter is linked more to structural changes than to density or porosity. Therefore, further analysis and a search for critical densities have been made on the basis of the snow-ice acoustic and elastic properties as a functions of $K_{\mathrm{p}}$. This has been achieved for the mean experimental data on elastic-wave velocities $V_{\mathrm{p}}$ and $V_{\mathrm{s}}$, and its squared ratio $A=\left(V_{\mathrm{p}} / V_{\mathrm{s}}\right)^{2}$, and also for all dynamic moduli of elasticity calculated from these parameters.

For example, as one can see from Figure 2, the Poisson's

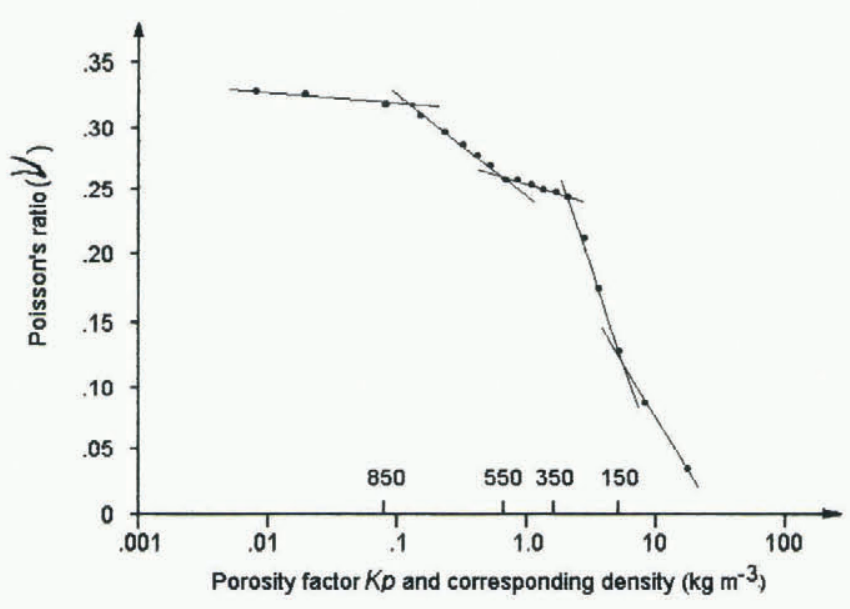

Fig. 2 Poisson's ratio vs the logarithm of porosity factor $K_{\mathrm{p}}$. 


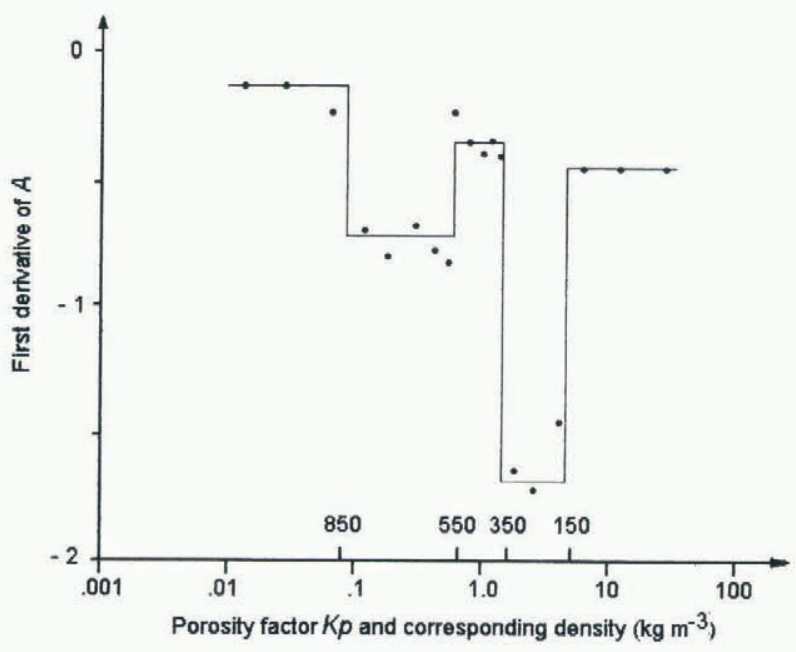

Fig. 3. First derivative of parameter A vs porosity factor $K_{\mathrm{p}}$.

ratio dependence as a function of the logarithm of $K_{\mathrm{p}}$ has several markedly sharp changes, within intervals between which the dependence is near to linear. A similar situation has been obtained for the other acoustic and elastic parameters for snow-ice formations. But, for Poisson's ratio, which depends highly upon the structure of the medium and is very sensitive to its transformation, the changes stand out most clearly and show a distinct possibility for pointing out the critical densities.

For the purpose of refining the values of critical densities, we have analysed the first and second derivatives of the acoustic and elastic parameters as functions of $K_{\mathrm{p}}$. Figure 3 shows an example of such a dependency.

The critical densities have been identified on the basis of the study of these derivative behavioural data. We have identified them as the narrow density intervals corresponding to changes in the dominant mechanisms of the snow-ice medium structural transformations which occur during densification. The critical densities obtained are:

$$
\begin{array}{ll}
\rho_{\mathrm{cr} 1}=130-160 \mathrm{~kg} \mathrm{~m}^{-3}, & \rho_{\mathrm{cr} 2}=330-360 \mathrm{~kg} \mathrm{~m}^{-3}, \\
\rho_{\mathrm{cr} 3}=530-570 \mathrm{~kg} \mathrm{~m}^{-3}, & \rho_{\mathrm{cr} 4}=820-840 \mathrm{~kg} \mathrm{~m}^{-3} .
\end{array}
$$

The behaviour of the derivatives between 550 and $800 \mathrm{~kg} \mathrm{~m}^{-3}$, as well as the results obtained by other authors (Maeno and others, 1978), give some reason to assume that the density $\rho_{\text {cr } 5}=700-730 \mathrm{~kg} \mathrm{~m}^{-3}$ is also critical; however, this fact requires further verification.

The critical-density values, evaluated from the analysis of the behaviour of different parameters, differ somewhat within the limits of the above-mentioned intervals. This is because changes in the dominant mechanisms of structuretexture transformations and formation of a new space order within the medium, occur in somewhat (narrow) intervals of density, and a further refining of the critical densities becomes physically unreasonable.

Our analysis has shown that, in the sub-ranges limited by the critical densities, the dependence of the acoustic parameters and almost all the elastic moduli on $K_{\mathrm{p}}$ can be described in double logarithmic scale by linear functions with a good degree of accuracy (the root-mean-square error of approximation does not exceed the error of the experimental data):

$$
\log Y=y_{1} \times \log K_{\mathrm{p}}+y_{2}
$$

where $y_{1}$ and $y_{2}$ are factors of approximation.

The $Y$-averaged values for studying medium parameters

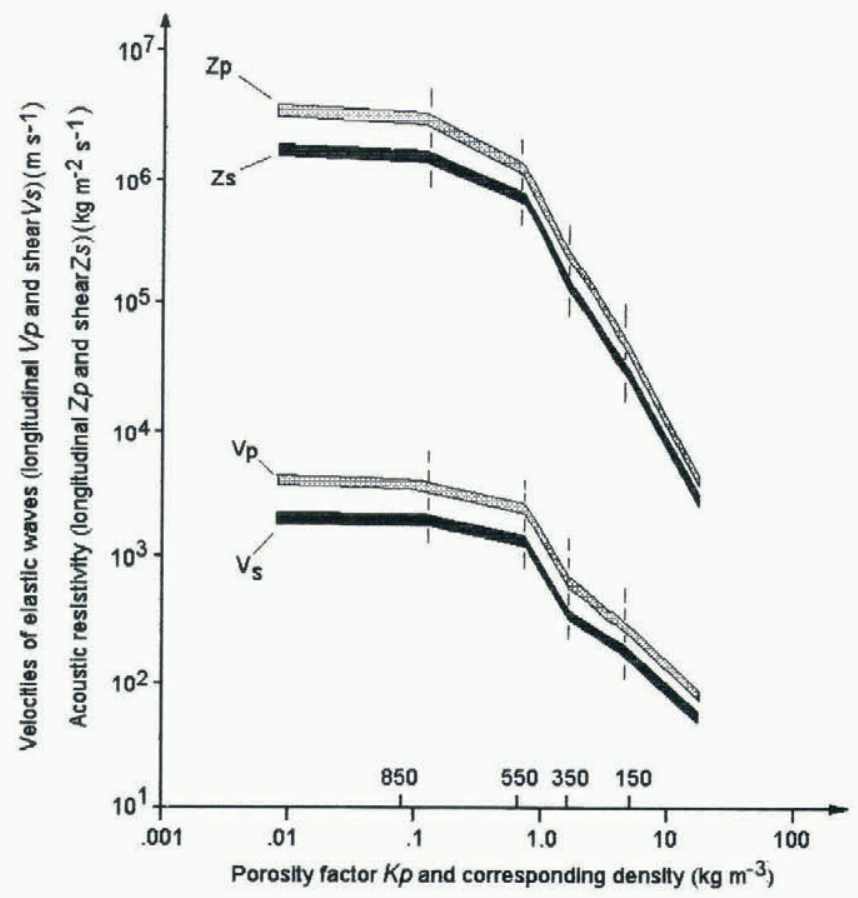

Fig. 4. Dependences of propagation velocities $V_{\mathrm{p}}$ and $V_{\mathrm{s}}$ and acoustic resistivities $Z_{\mathrm{p}}$ and $Z_{\mathrm{s}}$ of elastic waves in snow ice media on the porosity factor $K_{\mathrm{p}}$. Vertical dotted lines mark the critical densities.

are: propagation velocities of longitudinal $V_{\mathrm{p}}$ and shear $V_{\mathrm{s}}$ elastic waves in $\mathrm{m} \mathrm{s}^{-1}$ (Fig. 4); acoustic resistivity longitudinal $Z_{\mathrm{p}}$ and shear $Z_{\mathrm{s}}, \mathrm{kg} \mathrm{m}^{-2} \mathrm{~s}^{-1}$ (Fig. 4); elastic moduli: Young's $E$, shear $G$, bulk $K$ and Lamé's $\lambda$ in MPa (Fig. 5).

For Poisson's ratio $\nu$ and parameter $A$, the best approximation is obtained by using a half-logarithmic scale (Fig. 2):

$$
Y=y_{1} \times \log K_{\mathrm{p}}+y_{2} .
$$

The values of approximate factors (coefficients of Equations (1) and (2)) for each of the five density sub-ranges are given in Table 1 (see the units of parameters above in the text). It is necessary to note, that near the critical densities the processes of formation of snow-ice medium mechanical properties are so complicated that their description in joints of linear intervals is more complicated and the errors of ap-

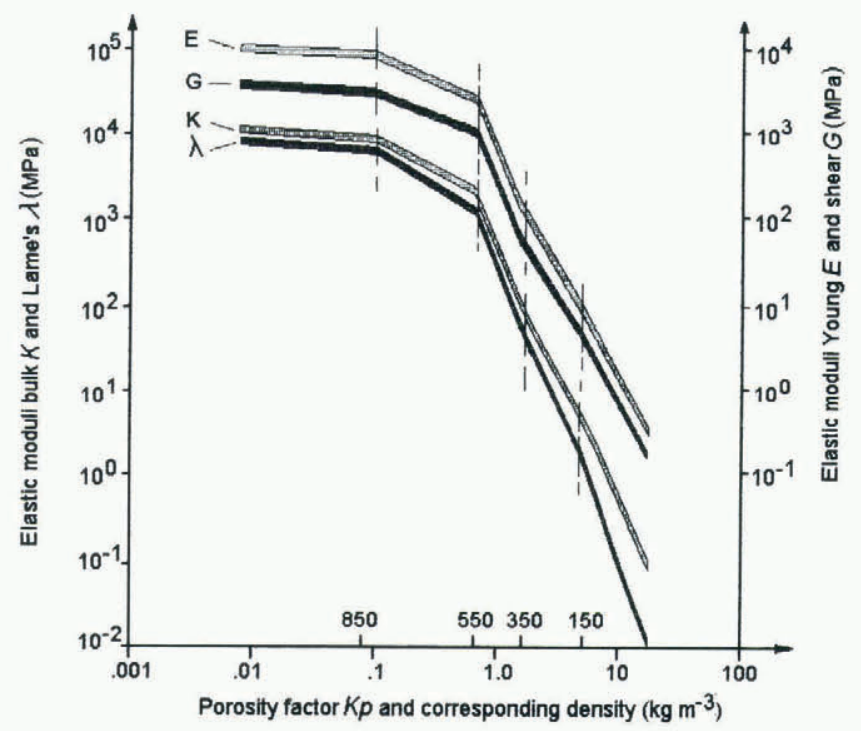

Fig. 5. Dependence of elastic moduli of $E, G, K$ and $\lambda$ on the porosity factor $K_{\mathrm{p}}$. 
Table 1. Values of approximate factors of Equations (1) and (2)

Parameters

Density sub-ranges $\left(\mathrm{kg} \mathrm{m}^{-3}\right)$

$50-150$

$150-350$

$350-550$

$550-800$

$850-917$

\begin{tabular}{rrrrrrr}
\hline$V_{\mathrm{p}}$ & $\mathrm{vp}_{1}$ & -0.9646 & -0.8152 & -1.5891 & -0.2530 & -0.0326 \\
& $\mathrm{vp}_{2}$ & 3.0981 & 2.9975 & 3.1616 & 3.3373 & 3.5306 \\
$V_{\mathrm{s}}$ & $\mathrm{vs}_{1}$ & -0.9235 & -0.6752 & -1.5651 & -0.2031 & -0.0228 \\
& $\mathrm{vs}_{2}$ & 2.8845 & 2.7175 & 2.9176 & 3.0990 & 3.2524 \\
$Z_{\mathrm{p}}$ & $\mathrm{zp}_{1}$ & -1.8712 & -1.5485 & -2.1376 & -0.5023 & -0.0630 \\
& $\mathrm{zp}_{2}$ & 2.9209 & 2.7058 & 2.8216 & 3.0451 & 3.4279 \\
$Z_{\mathrm{s}}$ & $\mathrm{ZS}_{1}$ & -1.8307 & -1.4078 & -2.1148 & -0.4522 & -0.5318 \\
& $\mathrm{zs}_{2}$ & 2.7079 & 2.4255 & 2.5777 & 2.8068 & 3.1499 \\
$E$ & $\mathrm{e}_{1}$ & -2.8270 & -2.1955 & -3.7397 & -0.6826 & -0.0797 \\
& $\mathrm{e}_{2}$ & 2.9940 & 2.5758 & 2.8984 & 3.3024 & 3.8195 \\
$G$ & $\mathrm{~g}_{1}$ & -2.7476 & -2.0883 & -3.7355 & -0.6588 & -0.0760 \\
& $\mathrm{~g}_{2}$ & 2.5891 & 2.1454 & 2.4989 & 2.9039 & 3.4022 \\
$K$ & $\mathrm{k}_{1}$ & -3.0159 & -2.6581 & -3.8573 & -0.8320 & -0.1083 \\
& $\mathrm{k}_{2}$ & 2.7683 & 2.5420 & 2.7389 & 3.1221 & 3.7536 \\
$\lambda$ & $\mathrm{l}_{1}$ & -3.6582 & -3.2422 & -3.8864 & -0.9201 & -0.1201 \\
& $\mathrm{l}_{2}$ & 2.7717 & 2.5106 & 2.5269 & 2.8020 & 3.6015 \\
$\nu$ & $\mathrm{n}_{1}$ & -0.1596 & -0.2979 & -0.0364 & -0.0769 & -0.0105 \\
& $\mathrm{n}_{2}$ & 0.2322 & 0.3417 & 0.2571 & 0.2486 & 0.3093 \\
\multirow{2}{*}{$A$} & $\mathrm{a}_{1}$ & -0.4199 & -1.7661 & -0.3542 & -0.7728 & -0.1752 \\
& $\mathrm{a}_{2}$ & 2.6352 & 3.5160 & 3.0765 & 2.9802 & 3.5878 \\
& & & & & & \\
\hline
\end{tabular}

proximation increase. Moreover, the changes of dependence at critical densities are not uniform and equally clear. For example, as one can see from Figure 4, the changes of elastic moduli $E, G, K$ near $\rho_{\mathrm{cr} 1}=130-160 \mathrm{~kg} \mathrm{~m}^{-3}$ are slight but nevertheless they exist (see Table 1).

Apparently, there is a sufficiently different influence of snow structure -texture transformation on the diverse parameters of the medium elasticity, especially in friable snow. Thus, the changes in Poisson's ratio at a critical density $\rho_{\mathrm{cr} 1}$ are more distinct (Fig. 2), than for other elastic moduli.

Model calculations (Golubev and Frolov, 1998) have shown that the above-mentioned critical densities correspond to snow-ice medium-grain packings with increasing dominant values of coordination numbers: $3,4,6$ and 1012 , and 8 for $\rho_{\text {cr5 }}$. These good correlations confirm the objectivity of the critical densities. As a result, the number of critical densities, determined or confirmed by our analysis, divides all variety of dry coherent snow-ice formations on the succession of the transition states with different dominant mechanisms of structure-texture transformations during the medium densification. The essence of these mechanisms is not yet clear and requires further studies.

The set of critical density for dry coherent snow-ice formations has first allowed us to describe without contradiction the main regularities of their acoustic- and elasticproperty changes in the whole density range. A similar approach could be extended to the strength and other physical properties of snow media.

\section{GONCLUSIONS}

The analysis dealing with peculiarities of acoustic and elastic properties of the snow-ice formations leads to the following conclusions:

1. The law of changes of acoustic parameters and elastic moduli of dry snow-ice media from light snow to massive ice cannot be described by the universal continuous function of density or porosity with an identical error in their whole range of densities.
2. There is a set of critical densities $(\sim 150, \sim 340, \sim 550$, $\sim 720$ and $\sim 830 \mathrm{~kg} \mathrm{~m}^{-3}$ ) limiting the density intervals in which a medium-structure re-organization is conditioned by different dominant mechanisms of densification of the snow-ice formations.

3. The best comparative parameter for the description of the laws is a porosity factor $K_{\mathrm{p}}$. The base regularities of the acoustic-parameters and elastic-moduli changes can be approximated by similar smooth functions of $K_{\mathrm{p}}$ within the density intervals, which are limited by the critical values.

4. The values of the approximation coefficients for all acoustic and elastic parameters are determined in each allocated interval of density that allow prediction of these properties for dry snow-ice formation's known density.

\section{ACKNOWLEDGEMENTS}

The studies described in this paper were achieved partly because of the financial support of the International Scientific Foundation (ISF) and Russian Government (joint grant $\mathrm{NJ} 5 \mathrm{Al} 100$ ), to which the authors are grateful.

\section{REFERENCES}

Anderson, D. L. and C. S. Benson. 1963. The densification and diagenesis of snow: properties, processes and applications. In Kingery, W. D., ed. Ice and snow: properties, processes, and applications. Cambridge, MA, M.I.T. Press, 391-411.

Bennett, H. F. 1972. Measurements of ultrasonic wave velocities in ice cores from Greenland and Antarctica. CRREL Res. Rep. 237.

Bogorodskiy, V.V. and V. P. Gavrilo. 1980. Led. Fizicheskiye svoystva Ice. Physical properties]. Leningrad, Gidrometeoizdat. (Sovremennyye metody glyatsiologii [Modern methods in glaciology].)

Bourbie, T., O. Coussy and B. Zinszner. 1986. Acoustique des milieuz poreaux. Paris, Ed. Technip.

Frolov, A. D. 1976. Elektricheskiye i uprugiye svoystva kryogennykh porod /Electric and elastic properties of frozen earth materials ]. Moscow, Nedra.

Golubev, V.N. and A. D. Frolov. 1998. Modelling the change in structure and mechanical properties in dry-snow densification up to ice. Ann. Glaciol., 26 (see paper in this volume).

Kohnen, H. 1977. Über die Beziehung zwischen seismischen Geschwindigkeiten und der Dichte in Firn und Eis. Z. Geophys., 38 (5), 925-935.

Kohnen, H. and C. R. Bentley. 1973. Seismoglaziologische Untersuchungen nahe Byrd Station, Antarktis. Arch. Meteorol. Geophys. Bioklimatol., Ser. A, 22(2-3), 311-324.

Macheret, Yu. Ya. 1977. Seismicheskiye metody v glatsiologii [Seismic methods in glaciology]. Itogi Nauki Tekh., Ser. Glyatsiol., 1, 41-86.

Maeno, N., H. Narita and K. Araoka. 1978. Measurements of air permeability and elastic modulus of snow and firn drilled at Mizuho station, East Antarctica. Memoirs National Institute of Polar Research, Special Issue 10, 62-76.

Mellor, M. 1977. Engineering properties of snow. 7. Glaciol., 19(81), 15-66.

Paterson, W. S. B. 1994. The physics of glaciers. Third edition. Oxford, etc., Elsevier.

Samoylyuk, V. I. 1992. Mekhanizm formirovaniya i razvitiya tekstury snezhnoy tolshchi [Mechanism of formation and development of the texture of snow sequence]. Mater. Glyatsiol. Issled. 73, 1991, 59-65.

Savel'yev, B. A., Yu. F. Durynin, Yu. E. Slesarenko and A. D. Frolov. 1967. Primeneniye ultrazvukovogo metoda dlya izucheniya stroeniya, sostava i fiziko-mekhanicheskikh svoystv sneynogo pokrova i otsenki lavinny opasnosti [Application of ultrasonic method to study of structure, composition and physico-mechanical properties of snow cover and avalanche risk evaluation]. In Tushinskiy, G. K., ed. Sneg $i$ laviny Khibin [Snow and avalanches of the Khibin mountains]. Moscow, Izdatel'stvo "Nauka", 240-257.

Voitkovskiy, K. F. 1977. Mekhanicheskiye svoystva snega [Mechanical properties of snow 7. Moscow, Nauka. SibirskoyeOtdeleniye. Institut Merzlotovedeniya.

Voronkov, O. K. and A. D. Frolov. 1992. Fizicheskiye svoystva gornykh porod pri otritsatelynykh temperaturakh [Physical properties of rocks and soils at negative temperatures]. In Dortman, N. B., ed. Petrofizika Petrophysics]. Vol. 3. Zemnaya kora $i$ mantiya [Earth core and mantle]. Moscow, Nedra, $43-65$. 